Article

\title{
Intermediary Propositions for Green Growth with Sustainable Governance
}

\section{Yongrok Choi}

Department of International Trade and Regional Studies, Inha University, 100 Inha-ro, Nam-gu, Incheon 402-751, Korea; E-Mail: yrchoi@inha.ac.kr; Tel.: +86-791-8381-0553;

Fax: +86-791-8381-0892

Academic Editors: Giuseppe Ioppolo, Malin Song and Seunghwan Myeong

Received: 24 September 2015 / Accepted: 3 November 2015 / Published: 5 November 2015

\begin{abstract}
This article gives an overview of the conceptual characteristics of sustainable development by searching the governance-oriented intermediaries. It shows how the new paradigm of green growth evolved through international consensus and how this paradigm of the public-private partnership (PPP) could work with the new propositions of intermediation. The historical context in the latter half of the 20th century is outlined, in which a paradigm shift toward PPP was caused by green growth policies. It emphasizes the governance, resulting in the propositions of the intermediary role of PPP by the SWOT matrix: facilitator, collaborator, network manager and service provider.
\end{abstract}

Keywords: public-private partnership (PPP); intermediary propositions; facilitator; SWOT matrix; green growth

\section{Introduction}

Within the turn of the 21 st century, humankind in the world has been experiencing rapidly-changing environmental conditions, resulting in the turmoil of a paradigm shift. Global warming and the environmental crisis worldwide are some of the phenomena of the fourth revolution of the green wave. For example, China faces huge environmental and air-cleanup challenges and costs, which it is undertaking on its own. The country estimates that pollution cost it roughly $3.5 \%$ of GDP in 2010, and life expectancy in the Northern provinces has decreased by about 5.5 years due to air pollution [1]. Almost 75 percent of China's biggest cities failed to meet the country's environmental protection standards, and only 19 of China's 74 larger cities met the standards. It is not uncommon for air 
pollution in most parts of China to breach levels considered by some experts to be hazardous. That has drawn much public ire and is a worry for the government, which fears any discontent that might compromise stability. At last, China declared a "war on pollution" at the opening of the annual meeting of parliament on March 2014. The government unveiled detailed measures to tackle what has become a hot-button social issue. Curbing pollution has become a key part of efforts to upgrade the economy, shift the focus away from heavy industry and tackle the perennial problem of overcapacity, describing smog as "nature's red-light warning against inefficient and blind development" [2]. China should get rid of the so-called global factory and instead take a new step toward qualitative selection to curb its growth potential. China will cut outdated steel production capacity by a total of 27 million tonnes in the year 2015, slash cement production by 42 million tones and also shut down 50,000 small coal-fired furnaces across the country. It is a huge loss serving as a bottleneck for growth potential.

By the same token, Korea and Japan have been experiencing the challenging issues of environmental disasters and, thus, strongly promoted eco-friendly sustainable economic development policies, so-called green growth. Now, green growth is not just an optional alternative, but the survival kit to overcome the environmental crisis across the world. Here, green growth means fostering economic growth and development while ensuring that natural assets continue to provide the resources and environmental services on which our well-being relies. To do this, it must catalyze investment and innovation, which will underpin sustainable growth and give rise to new economic opportunities. Sustainable development provides an important context for green growth. Here, sustainable development is defined, in general, as the development that meets the needs of the present without compromising the ability of future generations to meet their own needs [3]. Green growth is not an alternative way of sustainable development, but rather should be considered a subset of it, entailing an operational policy agenda that can help achieve concrete, measurable progress at the interface between economic needs and the environment [4]. That is the reason for this research in examining the feasibility of green growth policies in Northeast Asian countries.

Green growth is based on the theory of green economics, or greenomics in short, and it represents the fourth wave followed by the agricultural, industrial and IT industrial (or Internet-oriented) revolutions in world history. Greenomics is not just based on economics and interdisciplinary study, but is based on innovative or even creative multi-disciplinary studies, because greenomics, as a core of sustainable development, resulted from revolutionary technological innovation, likewise proceeding from the other three revolutions. From the perspective of sustainable development, economic growth and environmental protection cannot be integrated easily (coupling issue), and thus, it should be multi-dimensional and interdisciplinary at its core. However, the technical revolution has filled this missing link between economic demands and environmental protection, resulting in the feasibility of decoupling great potential for higher economic development and a better quality of life [5]. The reduction of greenhouse gases (GHG) may result in increased cost and/or productivity loss by traditional measures, while it creates new frontiers for renewable energy industries, green financing, etc. Moreover, green growth policies even increase the performance of the traditional "brick" industries by the creation of value: invisible long-term profits coming from the loyalty of huge interest groups. Global warming and the environmental crisis are no longer threats, but challenging opportunities for all countries, regardless of their economic level and/or cultural differences [6] (p. 7). Thus, we can call 
this phenomenon the new green wave, consisting of green growth policies and strategies, as the fourth revolutionary paradigm shift in human history.

Green growth is a much more practical concept in its details, compared to the more abstract terms and conditions of sustainable development, because it is based on practical, as well as feasible policies of governments and strategies of the private sector [7]. This brings the background of this research. The research shall overview most of the revolutionary factors of green growth in terms of a comparison of different policies and business strategies and examine their feasibility using the theoretical modeling of SWOT analysis. Based on the SWOT matrix, the research shall propose the feasible role and functions of the public-private partnership (PPP) as the best alternative intermediary to fill the missing link of the paradigm shift of green growth.

The remainder of this paper is organized as follows. In Section 2, the background of the green growth paradigm shall be examined. Section 3 shall analyze the paradigm shift of green growth by a comparative analysis in major countries, utilizing the SWOT matrix for the feasibility of the intermediation of the PPP. Section 4 shall conclude with the limits of this research and future prospects of green growth.

\section{Paradigm Shift to Green Growth}

\subsection{Historical Background of the Paradigm Shift}

The interrelationship between technology, productivity and growth has long been discussed along the history of human civilization. The importance of technological innovation cannot be overestimated with relation to the paradigm shift over time. It is the central determinant of the long-term success or failure of organizations [8]. Based on this technological innovation in history, the first agricultural revolution in the pre-history era was a great stepping stone for mankind to take off toward civilization for thousands of years. It is called the "classical economy" based on the self-sufficiency paradigm, represented by the famous Say's law; supply creates its own demand. The second industrial revolution, symbolized by steam and railroads in Britain during 1780-1860 and then in the following 300 years over the world, brought mass-production, mass-media and mass-consumption by the new paradigm of economies of scale; the more you produce, the higher the productivity you get. After World War I and II, the innovative inauguration of the computer and its consecutive ICT (information and communication technology) enhancement successfully transformed the whole of society with the new paradigm of economies of networking, serving as a new economic engine and for better life quality for 30 years. This new paradigm of economies of networking changed the mass-quantity-based economies into the quality-oriented smart revolution; the more you share information and experiences, the better you "create" values by group intelligence. Especially, the Internet has accelerated the new era of "knowledge" since the year 2000. The popular slogan in the industrial revolution era, stating that "information is power and money", has been changed, by the flood of information on the Internet, into the new slogan of "knowledge allows you to make smart decisions and perform smart activities". Here, new knowledge is defined as the information to select the best alternative [9].

The quality-oriented paradigm shift caused a diverse innovative way of thinking, and it caused the fourth revolution of the green wave, as well. The industrial revolution caused energy-intensive 
industries to dominate all of the economic development processes in every country. It caused too much environmental problems, such as deforestation, greenhouse gas emission, water pollution, etc., resulting in too frequent, unforeseeable disasters, such as floods, droughts, earthquakes, toxic air and water and melting down of glaciers. Every country should face the challenges of sustainable development under this unforeseeable disaster, and at last, sustainable development should became the core of qualitatively-enhanced economic policies.

In order to understand the historical background of the green wave, we need to systematically organize the trend of sustainable development first. Sustainable development, a concept that emerged in the context of a growing awareness of an imminent ecological crisis, could be more seriously addressed from the 1980s onward. From the perspective of policy-oriented practical terms, the United Nations Conference on the Human Environment (UNCHE) held in Stockholm, Sweden, in 1972 should be recorded as the first cornerstone toward the green wave, because it was the first major international gathering focused on human activities in relationship to the environment. The conference acknowledged that the goal of reducing human impact on the environment would require extensive international cooperation, as many of the problems affecting the environment are global in nature; caused by one country locally, while affecting other countries. Following this conference, the United Nations Environmental Program (UNEP) was launched in order to encourage United Nations agencies to integrate environmental measures into their programs in 1972. Following UNCHE and UNEP, the United Nations commissioned a group of 22 people from developed and developing countries to identify long-term environmental strategies for the international community. This World Commission on Environment and Development (WCED), better known as the Brundtland Commission, submitted their report, entitled "Our common future", to the UN in 1987 (WCED 1987). The Brundtland Report focused primarily on the needs and interests of humans and was concerned with securing global equity for future generations by redistributing resources towards poorer nations to encourage their economic growth in order to enable all human beings to achieve their basic needs (see Figure 1). The basic paradigm of the Brundtland Report became the platform for all of the following international action plans [10]. The green growth paradigm can be summarized by the triple bottom line (TBL) as an accounting framework with three parts of social, environmental (or ecological) and economic sustainability in Figure 1. Sustainable development policies should be socially equitable, economically viable and environmentally bearable. Unfortunately, it is not easy to find the best solution, but at the same time, it is not impossible to find the optimal path to control for all of these criteria.

Based on the Brundtland Report, the United Nations Conference on Environment and Development (UNCED), also known as the Rio Summit, Rio Conference or Earth Summit, was held to obtain a more systematic action plan to initiate sustainable development worldwide at Rio de Janeiro in 1992. An important achievement was an agreement on the Climate Change Convention (UNFCCC), which, in turn, led to the Kyoto Protocol. UNFCCC is an international environmental treaty and currently the only international climate policy venue with broad legitimacy, due in part to its virtually universal membership negotiated at the UNCED. The objective of the treaty is to "stabilize greenhouse gas concentrations in the atmosphere at a level that would prevent dangerous anthropogenic interference with the climate system" [8]. The treaty is considered legally non-binding, but provides a framework for negotiating specific international treaties (called "protocols") that may set binding limits on greenhouse gases (GHG). The UNFCCC was adopted in 1992 and entered into force in 1994 with 196 
member parties as of March 2014. The parties to the convention have met annually from 1995 in Conferences of the Parties (COP) to assess progress in dealing with climate change.

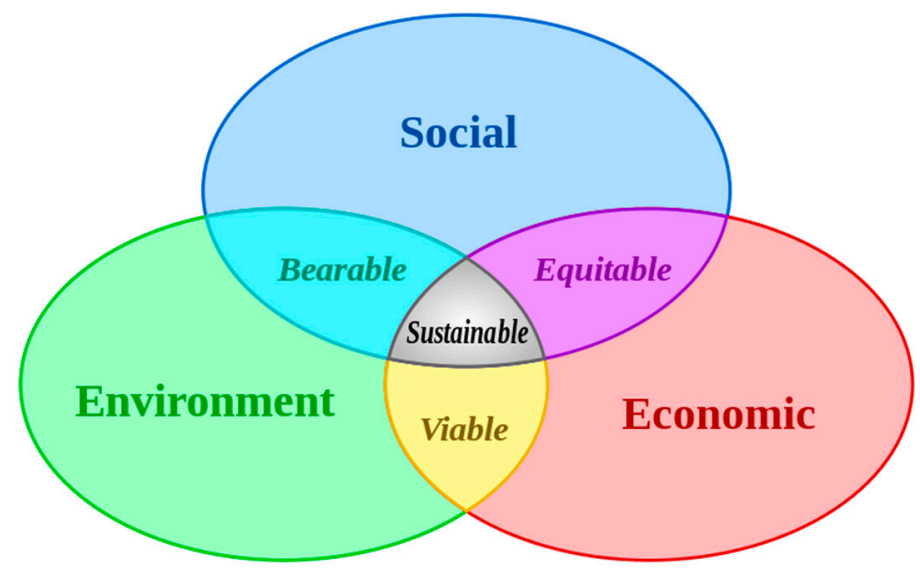

Figure 1. Paradigms of sustainable development (tree polar layer, TPL). Source: sustainable development from Wikipedia [11].

In 1997, the Kyoto Protocol was concluded and established legally-binding obligations for developed countries to reduce their six GHG emissions of $\mathrm{CO}_{2}, \mathrm{CH}_{4}, \mathrm{~N}_{2} \mathrm{O}, \mathrm{HFC}_{s}, \mathrm{PFC}_{s}$ and $\mathrm{SF}_{6}$. The Kyoto Protocol has had two commitment periods, the first of which lasted from 2005-2012 and the second 2012-2020. It made flexible mechanism for the successful governance of performance, such as Joint Implementation (JI), the Clean Development Mechanism (CDM) and the Emission Trading System (ETS). One of the first tasks set by the UNFCCC was for signatory nations to establish national greenhouse gas inventories of greenhouse gas (GHG) emissions and removals, which were used to create the 1990 benchmark levels for accession of Annex I countries to the Kyoto Protocol and for the commitment of those countries to GHG reductions. Updated inventories must be regularly submitted by Annex I countries. The Kyoto Protocol has been ratified by all of the other Annex I Parties. All Annex I Parties, excluding the U.S., have participated in the first Kyoto commitment period. Thirty seven Annex I countries and the EU have agreed to second-round Kyoto targets. Unfortunately, the U.S. has not ratified the Kyoto Protocol, and thus, it created a great bottleneck for all of the other parties to move toward the post Kyoto Protocol regime. Following the Kyoto Protocol, parties to the Convention (COP) have agreed to further commitments. These include the Bali Action Plan (2007), the Copenhagen Accord (2009), the Cancún agreements (2010) and the Durban Platform for Enhanced Action (2012). The 2010 Cancún agreements state that future global warming should be limited to below $2.0{ }^{\circ} \mathrm{C}\left(3.6^{\circ} \mathrm{F}\right)$ relative to the pre-industrial level. The Copenhagen Accord by COP-15 mentioned the "Copenhagen Green Climate Fund", and via Cancún agreements (2010), its governing instrument was adopted at the COP 17 (2012) in Durban.

The Green Climate Fund (GCF) is a fund within this framework of the UNFCCC founded as a mechanism to redistribute money from the developed to the developing world, in order to assist the developing countries with adaptation and mitigation practices to counter climate change. The GCF is based on the new Songdo district of Incheon, Korea. It is governed by a board of 24 members and initially supported by an interim secretariat. GCF will support projects, programs, policies and other 
activities for developing country parties using thematic funding windows [12]. It is intended to be the centerpiece of efforts to raise climate financing of $\$ 100$ billion a year by 2020 . This is not an official figure for the size of the fund itself, however. Disputes also remain as to whether the funding target will be based on public sources or whether "leveraged" private finance will be counted towards the total amount [13].

Over time, sustainable development has transformed into green growth, as the latter emphasizes more the fact that it is essential to "decouple" economic growth from unsustainable environmental pressures, such as those leading to global climate change. Decoupling of economic development from the pressure of environmental protection gave great opportunities for governments and companies to create values in an innovative way through technological development, and it was a great, imperative stepping stone to proliferate the green wave [14]. For example, under the sustainable development perspectives, it has been said that shifting the energy mix towards cleaner sources of energy and cleaning up polluting sources of energy, such as with carbon capture and sequestration, will also tend to raise energy costs, at least for a period of time. By contrast, under the green growth perspective, investments in energy-efficient "new" technology in industries can be cost effective, with benefits cumulating over time. Unfortunately, there is no automatic link between cleaner energy and better market performance, but these goals can often be made to be complementary.

This is the basic paradigm of green growth; the better the life quality, the healthier the economy and the more equitable is society due to the innovative way of decoupling. However, the green wave as the fourth revolution may have a flexible and diverse means of complementary promotion depending on the circumstances and cultural background of the countries. Every country should choose its own differentiated policies for its own green growth. There is no universally agreed-upon political paradigm. Nonetheless, the most important mission at this moment is to set up the global standards for this green wave, because "new" technology, "new" product and "new" green business affect not only the green growth economy, but also the whole of society, as the Internet revolution made a great impact on the daily life of all economic entities, as well as society itself. Unfortunately, the global standards as the cornerstone for the world to take off toward the next generation of the green wave are still in their midst. All of the new global standards should be defined in terms of new technology as the basic engine, new financing to boost this new innovative phenomenon and changing the way of thinking to maintain and expand the new phenomena. All of these three facets are related to the global standards, and thus, the competition for the global standards is rather fierce, even if it is invisible. All of the governments and global companies take these global standards to lead the global wave with their individual strategies or policy paradigms. Therefore, it is really important to compare these paradigms of countries to green growth in the next section.

\subsection{Comparison of the Green Growth Paradigms}

The global economy has been slowly recovering from the economic crisis in 2007 . However, the speed and performances are different from one country to another due to the surrounding circumstances and differences in the policy paradigm. This is especially true from the perspective of green growth. Most of the developing countries cannot emphasize the importance of environmental issues. Rather, these countries should put more efforts toward the rapid recovery of the ever-slowly-growing 
economies. Even so, their individual policy mechanisms and social paradigms are different from each other. Moreover, even one country may change its emphasis or paradigm over time. China has been called "the global factory", and "made-in-China" has meant the lowest price in the world. However, this is not so anymore, because recently, the Chinese government has become intensively aware of air pollution and the natural disasters arising from environmental aggravation. Since 2006, the Chinese 12th five-year economic development plan has begun to put more effort toward the feasibility of decoupling in major industries and, thus, investing more in technological innovation to decrease energy intensiveness and increase eco-friendly productivity. For this purpose, the Chinese government set up new rules and regulations with many more subsidies and promotional policies. It is quite clear that the Chinese government set up the new paradigm on green growth with government-led, regulatory-oriented policies [15].

Compared to China, the Korean government has taken a more rigid regulatory regime with the belief that the government-led policies shall result in much faster performance and higher efficiency to lead the global green growth [16]. This government-led paradigm on economic development has been successful, at least in the past, but no longer in Korea, because the economy has been enormously expanded with respect to its volume, and thus, it became much more complicated than before. Especially, the Korean economy has suffered from sluggish growth of the labor force and capital investment into its economy, thus experiencing an about $0 \%$ growth era at present. The input-promoted quantitative economic growth in Korea cannot no longer be sustained. Instead, innovation-oriented qualitative economic development is necessary with an aging society [17]. Moreover, the major companies in Korea, such as Samsung and Hyundai cars, are more aware of global competitiveness than local political pressure, because the Korean economy is based on international trade with an export-oriented economic structure. Therefore, the regulatory regime toward green growth is no longer efficient and effective in this innovation-oriented and very complicated economy.

Nonetheless, the Korean government hosted the Green Climate Fund (GCF) at Incheon in 2012. Thus, it has strongly promoted green growth policies since 2008. Based on the Framework Act on Low Carbon, Green Growth, the Korean government inaugurated the greenhouse gas and energy target management system (TMS) for the 470 largest companies since 2012 and carbon emission trading system (ETS) nationwide in 2015. The political paradigm for green growth is so firm in Korea, that the market should follow the optimal path toward green growth. It is noteworthy that most of the Korean companies and the public are very adaptive to the new trend and/or policies, and thus, there is optimism that the Korean economy will promote green growth strategies in a more pro-active way [18].

Compared to the other two Northeast Asian countries, Japan has taken the highest level of the government-led paradigm on green growth. It comes from the cultural background. Most of the private sector in Japanese tends to harmonize itself with the networking society, and thus, the social leaders of government and some intermediaries of business associations may have a strong impact on social activities and economic decisions. Even if the Japanese government does not clearly regulate much of the details of the green growth strategies, as long as the government propagates the objective goal of green growth, most companies and the public may follow without much reluctance [19]. Specifically, the Japanese government led the Kyoto Protocol, one of the strongest measures to curb $\mathrm{CO}_{2}$ emissions worldwide; thus, without many visible regulatory measures, the Japanese economy has been transforming slowly, but effectively toward green growth. However, the Japanese government may 
face the dilemma for green growth between normative leadership and the practical burden of green growth. This set off the Kyoto Protocol, and it successfully performed its commitment to decrease 6\% of carbon emissions compared to the basic year of 1990, as the leading Annex I country. However, the dropping of the USA and the passive attitudes of many other major countries with respect to the Commitment, such as China, made the Japanese government hold back from a more active role toward the post-Kyoto regime. Now, the Japanese government faces the utmost fatigue from the Kyoto Protocol regime and thus needs more strong leadership for more voluntary partnerships, not only from the outside of the country, but also from local companies and the public to re-take the challenging path of green growth [20].

As Northeast Asian countries take the government-led regulatory regime toward green growth, the opposite extreme case could be found in the United States. The basic paradigm of the United States may come from the passive intervention of the market by the government with the more market-friendly promotion of green technologies. The diverse economic policies related to green growth are not exceptional. Thus, the United States could not enter the Kyoto Protocol due to the strong opposition of the private sector against the government decision for green growth. Nonetheless, some local governments and global companies, such as California and Wal-Mart, have taken strong measures to utilize the new opportunities of green growth more aggressively with a regulatory frame, while most of the economy is experiencing the slow, but steady steps toward green growth. Even if there are several environmentally-friendly protective measures on the government side, still most of the green growth strategies are not yet ready for a market- and eco-friendly platform. Unfortunately, the market cannot respond effectively to the green growth paradigm, and it takes too much time for the market to find the right way toward global standards. Therefore, it is a great task for the government to lead the market more efficiently and effectively toward global green standards. Otherwise, it is afraid of the potential huge loss when it loses the leadership of the fifth green growth revolution worldwide. For this purpose, it may need to consider the strong connection to the private sector to actively lead the global trend of green growth.

On the contrary, the European Union (EU) takes another extreme paradigm on the spectrum of the government's role. With the successful implementation of the Kyoto Protocol, the EU Commission set up the Directorate-General for Climate Action (DG CLIMA) to lead the European Commission's efforts to fight climate change at the EU and international level. It runs the European EMS (Environmental Management System) with the mission to formulate and implement climate policies and strategies, to take a leading role in international negotiations on climate, to implement the EU's Emissions Trading System (EU ETS), to monitor national emissions by EU member countries and to promote low-carbon technologies and adaptation measures in 2010. EU is at the front in dealing with green growth activities with diverse efforts to promote the development of low-carbon technologies and adaptation measures, especially by creating regulatory frameworks to guide the deployment of these technologies and by providing diverse financial support. However, their regulatory platform is rather passive and related to many more promotional policies toward the incentive areas of green growth by green financing. Therefore, the paradigm of the EU could be promotional, even somewhat government led, and the financing approach by the EU is noteworthy. It introduced the carbon Emission Trading System (ETS), the first in the world, and expanded it much more aggressively than any other part of the world, even under the global economic crisis. The strong support of the ETS 
turned the environmental issues into purely internalized economies outside of external factors. Even if the ETS has had fluctuating prices, as well as concerns for the future of the ETS itself, it still covers almost all of the economic decisions, as well as the daily life of all of the public in the EU. Their positive reinforcement by green financing and government-led indirect suggestions to try to achieve non-forced compliance can influence the motives, incentives and decision making of companies and individuals, at least as effectively, if not more effectively, than direct enforcement of green growth. Moreover, the financing Nudge paradigm brought a strong partnership between the local government and the private companies in diverse projects for the enhanced adaptation toward green growth. This public-private partnership (PPP) is the core paradigm of the OECD, and thus, it sheds light on the future direction of the green wave for all of the countries.

The OECD has taken the lead in the international cooperation for green growth, since sustainable development has transformed into green growth with much more emphasis on decoupling the feasibility between urgent economic needs and long-term environmental protectionism. They published a series of green growth strategies and best alternative policies for the optimal path toward green growth. Especially, their emphasis on the PPP regime cannot be overestimated in the area of green growth. The government should provide the seed money and strategic platform for the public, which is afraid of the investment in green business, the invention of new technology or even the adoption of new technologies. Private companies might be aware of these new challenging initiatives of the government and participate in the new frontier of green growth more pro-actively (pumping policy). The feedback from these economic entities should guarantee the innovation of new standards, new platforms and new ways of life by government concession. This PPP requires no helper, but partners to enlarge their piece of the pie for all of the partners in the challenging future. Specifically, the government should not lead without the consideration of partners, and the private sector should provide more feedback for the market-oriented and performance-oriented paradigm of green growth under this PPP mechanism.

Based on all of the comparative analyses of the government policy paradigms on sustainable development, we need some harmonized new paradigm of sustainable development on behalf of the role of the government and the private sector together. As shown in Figure 2, the highly-regulated government-led paradigm of green growth policies in Northeast Asian countries should decrease the leading role of the government, while increasing the partnership with the private sector. Otherwise, the governments in the Northeast Asian countries may face strong antipathy from the private sector due to the over-emphasized regulation and the interventions of the government. On the contrary, the government of the United States should provide more regulatory enforcement of green growth and promote active participation by the private sector more effectively in a short amount of time. In this way, the new PPP paradigm could work effectively to create new global standards for green growth, and every economic entity is willing to participate in these new standards to create value by the pro-active adaptation of these new global standards. Based on Figure 2, it is quite safe to conclude that the new paradigm for green growth should be based on the active partnership between the public and the private sector for sustainable governance [14,18]. Even so, there is too diverse of a spectrum of this PPP mechanism, from the loose, indirect Nudge strategies of the government, to the strong, direct intervention of the government with the "help" of private partners. Therefore, the PPP is not the only solution for a harmonized paradigm of sustainable development. The organization and its surrounding conditions of the PPP are much more important for efficient and effective performance. In the one 
extreme of the Korean PPP, it may incur a moral hazard in the private sector due to the strong support of the government, while the other extreme case of the United States type of PPP may result in the laissez-faire non-obligation on the performance, because everybody's work is nobody's work. That is the reason for the research to complement the contents of the PPP in terms of a feasibility study in the following chapter.

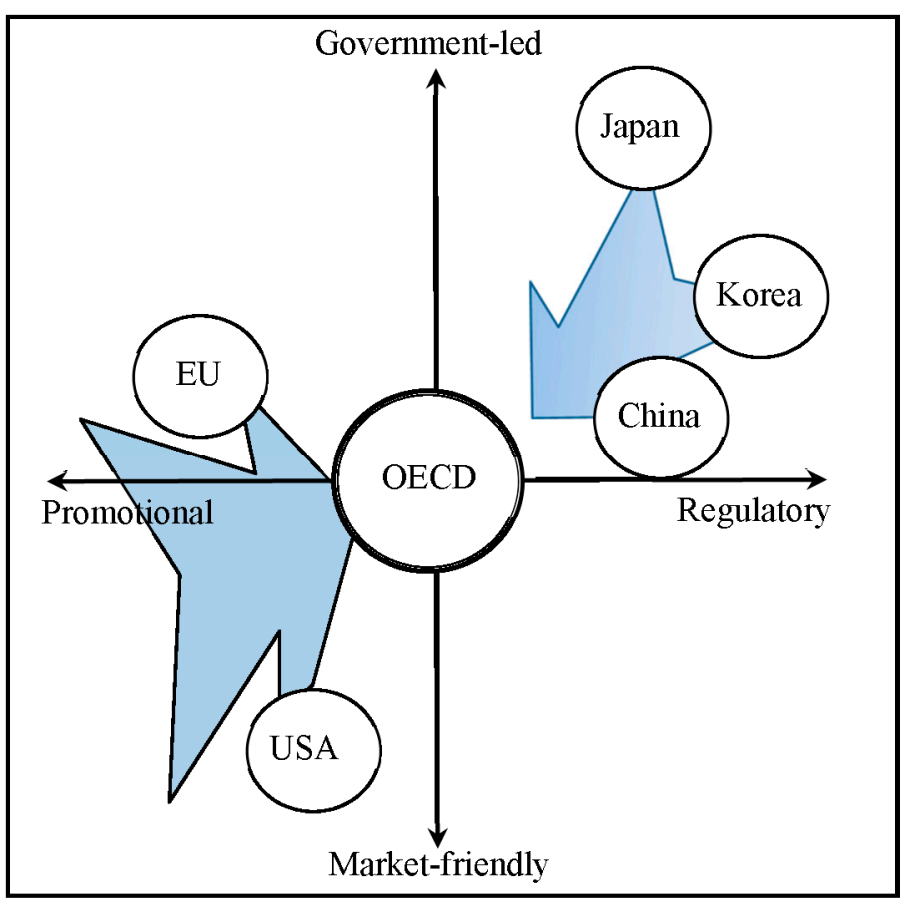

Figure 2. Paradigms of the government policies.

We examined the comparative analysis on the policy paradigm from the global perspective to the country by country cases. Since we conclude that the PPP is not optional, but necessary for all of the countries to promote green growth, it is time to examine more in-depth the contents of the role and functions of the PPP mechanism for green growth. Because the most important issues for green growth are categorized by the harmonized, yet more pro-active partnership between the PPP, we shall use the well-known SWOT matrix approach in the next section in order to find out the optimal propositions for the role and functions of the PPP mechanism in more detail.

\section{SOWT Matrix and the Propositions of the PPP Mechanism}

\subsection{Consultocracy in the Green Growth Economy}

There are many theories about how to use public resources to combat climate change, but most of the research concluded that there is somewhat a missing link between the implementation of these theoretical suggestions and the resulting performance because of the lack of a harmonized partnership in the process. Since the green growth policies result in invisible values most of the time in the long-term via very complicated and complex processes with the involvement of diverse interest groups, these policies easily fall into pit-falls, for which the policies "effectively" achieve the 
quantitative objectives of green growth, but still, it is clear that many of the achieved outputs are instantaneous and show up only with misused or wasted resources [21].

Nobody wants the achieved outputs and/or there to be no guarantee that this performance could be maintained over time. Therefore, sustainable performance over time is the key for the governance in green growth. There are many exemplary case studies for which policies are implemented successfully, but nobody wants them due to the one-way operation of the government [14,21]. Therefore, it is also necessary to organize an efficient and policy-effective intermediary for the harmonized PPP system to promote the feedback between the government and the private sector, resulting in sustainable value creation. Specifically, it is really difficult to develop or even to innovate new green technologies under a government-led economy. Moreover, most of the newly-developed technologies are rather inventor-oriented, and thus, it is quite difficult to match them with the right demanding partners, even under a market-friendly economy. Small and medium companies, which make up more than 60 percent in all of the countries, could not easily find where and how to get the best support that is already provided by the government and/or the right technologies that are newly-developed in the market. Thus, the intermediation of this match-making for the new challenging frontier of green growth is the core of successful and sustainable governance. By the same token, for the feasibility analysis and following the long- and short-term plan, the third party with the new challenging green growth project is definitely required to search for the right information, to evaluate the information and to finalize it for public fund-raising.

Unfortunately, there are too many operational missing links to obtain sustainable performance. For example, the government creates a project for the PPP, such as a forest business association to plant trees to protect deforestation. This policy could be "effectively" implemented by the PPP in the short term only. There is no guarantee that these newly-planted trees will grow well, because the PPP has no concern for these services in the long-term. All of these operational missing links between public policy and market performance require a survival kit for the intermediation under the green growth regime, but unfortunately, it is really difficult for companies, even for governments to find a solution by themselves and/or a cooperative solution with the potentially best partners. Therefore, it is quite necessary to find the role and functions of these intermediaries to fill the missing link between the cooperative networking partners for the governance of sustainable performance [22]. It is especially true that in our research, as the OECD pointed out, the PPP system is crucial as the best intermediary for the internalization of all externalities of the interested groups and of their related future challenges.

Most of the countries do utilize an intermediary for the implementation of government policies on green growth. In Korea, for example, there are several voluntary schemes for PPP projects toward green growth: the agreement on energy savings, certification for environmentally-friendly agricultural products, certification for use of the environmental seal, designation of environmentally-friendly companies, green building certification and voluntary environmental management agreements. However, most of these intermediaries have serious "consultocracy" problems, and thus, most of these programs and projects just have showing-off effects in many cases. Here, consultocracy means that the supplier-, developer- or policy maker-oriented intermediaries argue over and confirm the feasibility of new systems, new methods and new strategies for the market without enough consideration of market factors and, thus, resulting in the lack of economic efficiency, company capacity and the technical 
interface with the legacy system, due to its autocracy on the decision [21] (p. 38). Thus, the consultocracy causes enormous waste of resources and time, due to the lack of a governance-oriented mediating role. Unfortunately, this comes from the inefficiency of a large organization, such as government-led policy implementation [23]. In the following section, we shall try to examine the role and functions of these intermediaries in terms of their appropriate role and functions among the partners of all economic entities on the complicated, and yet complex, implementation process of green growth policies.

\subsection{Environmental Conditions for Green Growth Intermediation}

As shown in Figure 2, most of the Asian countries are promoting government-led green growth policies, because there are some conflicts of interest between the public and businesses, at least in the initial stage of green growth. Since the government could not intervene in the market in a direct way effectively, most of the government-led projects could be implemented by intermediaries, such as the independent official authorities (public companies), business associations, academic third parties, etc. The PPP is the best platform of this kind of third sector of the economy to handle cooperative challenges in general. When the government cannot perform effectively, but wants to intervene in the private economy with the indirect Nudge strategy, it may use a diverse PPP as the third part of the economy, and this PPP could gain a diverse spectrum from the government-owned operating public companies to the negligible portion of ownership on the stock market with the majority shares operated by private companies.

The motivation of these diverse PPP could be found from the political strategic consideration. Since the green wave requires the utmost participation of almost all of the economic entities, it is not easy to convey the right signal by policies only. Fortunately, there is global consensus on the pressure for green growth, and this may require the public and private sectors to cooperate with highly motivated global consensus. Due to the complicated, complex process with very vague performance, which in general cannot be measured easily and effectively, green growth should be supported by the strong participation of all. The public should be aware of the long-term effect of the eco-friendly strategies and, thus, be keen to provide invisible pressure on companies for their transformation to the green platform, and this may result in unexpected new business opportunities. POSCO, a steel-manufacturing company, has great pressure from the government and the public, and thus, it concentrated on greening strategies of the entire manufacturing process. They noticed that there are is too much steel scrap thrown out from the manufacturing process as waste and, thus, invested to decrease and collect all of these steel scraps, and finally, this waste of steel scraps brought much extra profit, as well as brand loyalty as an eco-friendly company. When the company found that the new efforts toward green growth do not have costs, but investment results in visible and invisible values, they could participate more aggressively in a proactive partnership with the government. They have to harmonize short-term profits and long-term values created by the loyalty of the interest groups. Additionally, the government should utilize this PPP as the flagship to initiate new challenges of innovation, new technology adoption and new green strategies and to get feedback and the voluntary, but necessary, participation of companies.

There are many opportunities for these PPPs to be handled more effectively to create values on the cooperative network. Since they get indirect support from the government, it is easy to enter a new 
market, with new innovative technology and a new field of projects. Moreover, the private partners may provide better resources to examine the feasibility, providing more efficient solutions for possible bottlenecks and implementing a green mission more effectively. Most of all, this PPP could be a third part of the project, which means that it can avoid any subjective mistake, either by the government or by the private sector. It also provides a very flexible approach to handle the projects that all of the participants could contribute to their strategic strength. It could obtain strong indirect guarantees from government participation, while it could recruit the best partners to mobilize their best resources. Specifically, green growth is an area for international cooperation, and thus, government participation is very important for the other project partners to obtain a transparent and predictable mechanism for their major tasks, to harmonize with the global standards, as well as the concession of the other countries.

However, the surrounding condition of PPPs does not seem to be very effective for the sustainable operation of a cooperative network by all of the participants, mainly due to the uncertainty regarding the policies or policy risks. The mission of PPPs requires quantitative performance, in the short term in general, and thus, it does not care about the future feedback from the users and the markets. If the policies give a good signal of the predictable, transparent operation of PPPs, it will be very beneficial for private companies to participate in this guaranteed opportunity. Unfortunately, government policies tend to be short term oriented, and thus, private partners could not invest more for this unsustainable partner of the government. Instead, they may take a more passive position to take advantage without much contribution. Especially, when there is some conflict of the interest between the partners, the third party of the PPP could not effectively harmonize the interest and, thus, chooses the second best on behalf of the government, as the political situation changes, which could result in worse performance than the private competitors. Unfortunately, there are many diverse conflicts of interest, and thus, it is not easy for all partners to participate in this collaboration network voluntarily and pro-actively to create values for all. Thus, the voluntarily, pro-active partnership for all of the members in the collaboration network is required among the interest groups, and only when the government can adopt market-oriented strategies, can the PPP, as the network manager of the collaboration network, fill the missing link.

\subsection{Internal Capacity of the Green Growth Intermediaries}

The strongest factor for the PPP, as an intermediary to find and fill the missing link of the collaboration network, could be found in that it is supported and thus has guaranteed performance at least in quantitative terms in the short run. The government participation makes the PPP more active to promote the policy goal. It could bring the best combination of partners, as well, in the field, due to the strong incentives and support of the government. For example, Korea was far short of enough telecommunications in the 1980s. It also had great challenges in its research and development capacity in the field, as well. When the Korean government set up the new entity of Korea Telecom (KT), as a kind of PPP strongly supported by the government, KT created a time division exchange (TDX) system as the fourth new innovation in the world. Moreover, the efficient installation of the telecommunication network nationwide by KT made Korea one of the top leading countries of IT in the Internet era. This kind of PPP could easily access diverse resources with dynamic flexibility and the best partners in their collaboration network, thus reducing any procedural cost. 
However, the weakest factor of the PPP may come from the consultocracy. Since most of the PPPs are based on a certain project with a political mission, they tend to stick to the goal of the policy mission and, thus, easily forget the results of it. Instead, they emphasize short-term achievement, because most of the policies require short-term benchmarks. For example, in order to prevent deforestation, they just plant the same kind of trees, in general efficiently and especially "effectively", but one kind of tree could be in danger of attack by injurious insects and even susceptible to fire. The more government controls the management, the higher the consultocracy that could result. By contrast, if there are certain guarantees by the government with very flexible operation of the mission, then the moral hazard of non-responsible decision makers could be easily identified. In 2004, the Korean government pronounced its regional economic development five-year plan, promoting the development of selective regions with a total budget of 66.6 billion dollars through 2008. The core project for the policies is based on the Regional Innovation System (RIS). To promote RIS, the government set up 14 RIS boards nationwide. As PPP-based intermediaries of RIS, the 14 regional boards are made up of 725 people in Korea. Unfortunately, most board members are from universities. Moreover, 11 of 14 chairpersons of these boards come from universities, as well. Moreover, most of these intermediaries from universities and faculties are not active in participating in commercial activities, because they do not have any obligation. Some RISs in Korea are just renamed as the traditional brick and mortal industry complex, such as Kumi, whereas others are newly made in the green fields of mountain regions without any infrastructure at all. Because there are no performance-based incentives or obligations for financing of the strategic fields, most RIS boards do not consider much their selection or management of RIS. These missing links between these 14 RIS boards and their regional operations prohibits continuing their mission, and when the new President is elected, all of these PPPs will be gone with much waste of national resources [24].

\subsection{SWOT Matrix and the Proposed Paradigm for Green Growth}

Based on the above surrounding environmental conditions and the internal capacity analyses of the PPP as an intermediary, we can integrate its strengths (S) and weaknesses (W), its opportunities (O) and the threats $(\mathrm{T})$, resulting in the SWOT matrix model. As shown in Table 1, the internal capacity analysis gives the facts about the strengths and weaknesses of the PPP as an intermediary, while the external surrounding environment analysis brings the opportunity and threat factors. From this summary of the facts, we can draw the future strategies for market- and performance-oriented governance. It should be called a strategy, because it comes from the current situation and the internal facts, resulting in more dependable, feasible scenarios of the strategic alternatives [10].

First of all, the PPP should increase the role of the facilitator (SO strategy, facilitator proposition). Based on the strong support of the government and the global consensus toward green growth, the PPP intermediary should make an effort to innovate new technology, to transform its business into the green growth platform with more eco-friendly strategies and to create new products and new businesses. As an early adopter of green growth, it should shed light for all of the interest groups on understand this new direction as being much more valuable than any other traditional legacy system. This requires a pro-active role to invite the potential partners to enter the collaboration network in a more voluntary manner with their own contribution to value sharing. 
Table 1. SWOT matrix strategies.

\begin{tabular}{|c|c|c|c|}
\hline \multirow{2}{*}{\multicolumn{2}{|c|}{ External Environment $\quad$ Internal Capacity }} & Strength & Weakness \\
\hline & & $\begin{array}{l}\text { - } \text { Government Support } \\
\text { - Best Private Partner } \\
\text { - Flexible Management }\end{array}$ & $\begin{array}{l}\text { - Consultocracy (Moral } \\
\text { Hazard) } \\
\text { - Low Motivation } \\
\end{array}$ \\
\hline Opportunity & $\begin{array}{l}\text { - Global Consensus } \\
\text { - New Biz. Opportunities }\end{array}$ & $\begin{array}{l}\text { Increasing Role for Facilitator } \\
\text { (SO Strategy) }\end{array}$ & $\begin{array}{c}\text { Increasing Role for Network } \\
\text { Manager (OW Strategy) }\end{array}$ \\
\hline Threat & $\begin{array}{l}\text { - Low Partnership } \\
\text { - Policy Risk }\end{array}$ & $\begin{array}{c}\text { Increasing Role for } \\
\text { Collaborator (ST Strategy) }\end{array}$ & $\begin{array}{c}\text { Increasing Role for Service } \\
\text { Provider (TW Strategy) }\end{array}$ \\
\hline
\end{tabular}

The second strategy coming from the weakness and opportunity factors should be based on the increased role as the network manager (OW strategy, network manager proposition). As green growth requires complicated and complex processes from the input to the finally-created values in the long term, there are conflicts from diverse interest groups. The most important role for the PPP intermediary should be networking with them more effectively for cooperation and to harmonize their conflicting interests in terms of bearable, equitable and viable cooperation, as shown in the Figure 1. Networking and its operation for all of the interest groups are crucial for the sustainable performance of green growth.

The third strategy to utilize the strengths and to overcome the threats should be based on the enhanced role as the collaborator (ST strategy, collaborator proposition). There are too many helpers in government-led projects, but no partners at all, in general. The helpers are not responsible for the performance and, thus, just provide consulting under too abstract and ideal conditions. Neither can they give any proactive contribution, because of the lack of any practical incentives. Therefore, in order to continuously promote the green growth collaboration, all of the interest groups should not just be outsiders, but inside partners with a proactive contribution with appropriate rights and responsibilities to share with each other. This collaborator proposition expels the consultocracy, because those that act only as helpers can no longer contribute with lip service alone, while partners participate with a strong motivation from the value sharing system.

The last strategy coming from the weakness and opportunity factors should be based on the increased role as the service provider (TW strategy, service provider proposition). The PPP intermediary should provide all of the necessary information and potential resources for the participants. The diverse background of the partners in the collaboration networking may lack exact requirements or future challenges in detail, and the network manager should give all possible support to the participants to communicate more effectively and find their needs. For example, a technician only develops new innovation by his or her own idea, and this green technology may not match the demand of companies due to the lack of market information, time and funding. In this case, the network manager should provide diverse options to match this new green technology with the demanding partners.

\section{Conclusions}

The green growth policies worldwide have been promoted by new challenges to protect the environment, to find and develop new green technologies and businesses and to integrate all of the possible interest groups for equitable, viable and bearable development. Followed by the third revolution 
of the Internet, this fourth revolution of green growth clearly makes all of the economic entities become aware of the environmental impact and sustainable resource utilization. However, there is still a high level of doubt regarding green growth, especially from the companies' perspectives. Most companies regard this new green growth paradigm as an additional burden with much cost, resulting in the weakening of international competitiveness. In order to transform this passive attitude of the private sector into more proactive partnerships in the new frontier of green growth, the public-private partnership (PPP) could be the best alternative as an intermediary to fill the missing link in collaboration networking.

However, the PPP, as the harmonized third party, could not achieve successful governance due to internal bottlenecks, as well as external surrounding difficulties. In order to utilize the opportunities and strengths and to overcome the threats and weakness, this paper suggested four propositions as the appropriate intermediary: facilitator proposition, network manager proposition, collaborator proposition and service provider proposition. Even if these propositions better explain the role and functions of the PPP, still, the paper could not deliver more details about these propositions with comparative case studies. This will be the tasks for future extensions of this research.

\section{Acknowledgments}

This work was supported by the National Research Foundation of Korea Grant funded by the Korean Government (NRF-2014S1A5B1011422).

\section{Conflicts of Interest}

The author declares no conflict of interest.

\section{References}

1. Michael, L. Yellow Dust Storm Carries Chinese Pollutants to Korea. Available online: http://blogs.blouinnews.com/blouinbeatsciencehealth/2015/02/24/yellow-dust-storm-carrieschinese-pollutants-to-korea/ (accessed on 24 February 2015).

2. Reuters News. China to "Declare War" on Pollution, Premier Says. Available online: http://www.reuters.com/article/2014/03/05/us-china-parliament-pollution-idUSBREA2405W20140305 (accessed on 4 March 2014).

3. World Commission on Environment and Development (WCED). Our Common Future; Oxford University Press: Oxford, UK, 1987; p. 43.

4. OECD. Towards Green Growth. Available online: http://www.keepeek.com/Digital-AssetManagement/oecd/environment/towards-green-growth_9789264111318-en\#page4 (accessed on 24 September 2015).

5. Chen, S.Y.; Xie, Z. Is China's e-governance sustainable? Testing Solow IT productivity paradox in China's context. Technol. Forecast. Soc. Chang. 2015, 96, 51-61.

6. Fankhauser, S.; Bowen, A.; Calel, R.; Dechezleprêtre, A.; Grover, D.; Rydge, J.; Sato, M. Who will win the green race? In search of environmental competitiveness and innovation. Cent. Clim. Chang. Econ. Policy Work. Pap. 2013, 23, 902-913. 
7. Du Pisani, J.A. Sustainable development-historical roots of the concept. Environ. Sci. 2006, 3, 83-96.

8. Munir, K.A. Competitive dynamics in face of technological discontinuity: A framework for action. J. High Technol. Manag. Res. 2003, 14, 93-109.

9. Yongrok, C. Global e-Business Management: Theory and Practice; Bomyeong Books: Seoul, Korea, 2014; p. 14.

10. UNFCC Report. Available online: http://report.mitigation2014.org/drafts/final-draft-postplenary/ ipcc_wg3_ar5_final-draft_postplenary_chapter13.pdf(accessed on 24 September 2015).

11. Sustainable Development: Wikipedia. Available online: https://en.wikipedia.org/wiki/File: Sustainable_development.svg (accessed on 1 November 2015).

12. United Nations Framework Convention on Climate Change (UNFCCC). Transitional Committee for the Design of the Green Climate Fund. Available online: http://unfccc.int/cooperation_and_ support/financial_mechanism/green_climate_fund/items/6902.php (accessed on 23 November 2011).

13. Institute for Policy Studies, Green Climate Fund, A Glossary of Climate Finance Terms. Available online: http://climatemarkets.org/glossary/green-climate-fund.html (accessed on 23 July 2013).

14. Choi, Y.; Ning, Z. Introduction to the Special Issue on "the Sustainable Asia Conference 2014". Sustainability 2015, 7, 1502-1695.

15. Gao, P. Government in the catching-up of technology innovation: Case of administrative intervention in China. Technol. Forcast. Soc. Chang. 2015, 96, 4-14.

16. Kim, K.; Leipziger, D.M. Korea: A Case of Government-Led Development; World Bank: Washington, DC, USA, 1993.

17. Rim, C. Korea's Age Boom: How South Korea is Addressing the Reality of Low Fertility and a Rapidly Aging Society. Available online: http://journal.aarpinternational.org/a/b/2013/02/KoreasAge-Boom-How-South-Korea-is-Addressing-the-Reality-of-Low-Fertility-and-a-Rapidly-AgingSociety (accessed on 24 July 2015).

18. Choi, Y. Introduction to the special Issue on "Sustainable e-Governance in Northeast Asia: Challenges for Sustainable Innovation”. Technol. Forcast. Soc. Chang. 2015, 96, 1-3.

19. Hideyo, K. Corporation Japan; Ihlsin Sa Publishing Co.: Seoul, Korea, 1998. (In Korean)

20. Light, A. Has Japan Killed the Kyoto Protocol? Even If It Has There's Still Hope for a Climate Agreement (web-article). Available online: https://www.americanprogress.org/issues /green/news/ 2010/12/08/8733/has-japan-killed-the-kyoto-protocol/ (accessed on 8 December 2010).

21. Choi, Y. The role of intermediation on the international aid for the governance of technical training program. Technol. Forcast. Soc. Chang. 2015, 96, 32-39.

22. Choi, Y.; Yu, Y. The influence of perceived corporate sustainability practices on employees and organizational performance. Sustainability 2014, 6, 348-365.

23. Harvey, L. X-efficiency. In The New Palgrave Dictionary of Economics, 2nd ed.; Palgrave MacMilan: London, UK, 2008.

24. Choi, Y. Optimizing risk management for the sustainable performance of the regional innovation system in Korea through met mediation. Hum. Ecol. Risk Assess. 2009, 15, 270-280.

(C) 2015 by the author; licensee MDPI, Basel, Switzerland. This article is an open access article distributed under the terms and conditions of the Creative Commons Attribution license (http://creativecommons.org/licenses/by/4.0/). 